Scientific paper

\title{
Transport of External Lithium Along Phase Boundary in LiF-Ti Nanocomposite Thin Films
}

\author{
Hao Zheng, ${ }^{1,2}$ Rui Wang, ${ }^{1}$ Jieyun Zheng, ${ }^{1}$ Jian Gao ${ }^{1,3}$ and Hong $\mathrm{Li}^{1, *}$ \\ ${ }^{1}$ Beijing National Laboratory for Condensed Matter Physics, Institute of Physics, Chinese Academy of Sciences, \\ Beijing, 100190, P. R. China \\ ${ }^{2}$ Institute of Materials for Mobile Energy, School of Materials Science and Engineering, Shanghai Jiao Tong University, \\ Shanghai, 200240, P. R. China \\ ${ }^{3}$ Materials Genome Institute, Shanghai University, Shanghai 200444, China \\ * Corresponding author: E-mail: hli@iphy.ac.cn \\ Phone: +861082648067
}

Received: 14-02-2016

This paper is dedicated to the memory of Prof. Janez Jamnik and his pioneer research on space charge layer effect in energy storage materials

\begin{abstract}
The electronic and ionic conductivity of the LiF-Ti nanocomposite films prepared by the co-sputtering have been investigated by the method of impedance spectrum (IS), current-voltage curves (IV) and isothermal transient ionic current (ITIC) measurements. It is found that the ionic conductivity of the obtained LiF-Ti nanocomposite film is very low. After electrochemical and chemical lithiation, ionic conductivities of the lithiated composite films are increased to be $10^{-3}$ and $10^{-4} \mathrm{~S} / \mathrm{cm}$ separately. This phenomenon indicates that the phase boundary between LiF and Ti could be the ionic conducting channels for external lithium in the LiF-Ti nanocomposite. Our results suggest a new strategy to design ionic or mixed ionic conductor.
\end{abstract}

Keywords: LiF-Ti, nanocomposite, thin film, chemical lithiation, ITIC, ionic transportation

\section{Introduction}

Transport behaviours of ions in solid can be classified into four types: ${ }^{1-7} 1$ ) motion of ions through vacancy or interstitial sites in a defected host lattice; 2) diffusion of ions in the free space through the segment wriggle of a polymer; 3) diffusion of ions on the surface of a solid; 4) diffusion of the ions along or across the interfaces between grains or phase. The later one has attracted wide attention. ${ }^{8-12}$ Nearly in all investigated heterogeneous polycrystalline or multiple phase composite or heterogeneous junctions systems, at least one phase at the side of the interface is an ionic conductor. The charge carriers come from at least one phase and ions transport along or across the phase boundaries influenced by the space charge layer effect. ${ }^{3}$

In searching for new reversible electrode materials for Li-storage, conversion type materials have attracted wide attention. It is found that lithium could electrochemically extracted from converted $\mathrm{M}-\mathrm{Li}_{2} \mathrm{O}(\mathrm{M}=\mathrm{Fe}, \mathrm{Co}$, $\mathrm{Ni}, \mathrm{Cu}$ ) nanocomposites. ${ }^{13}$ This means that chemical bonding between $\mathrm{Li}$ and $\mathrm{O}$ can be broken and lithium ions should be mobile in such nanocomposite.

Later in 2003, the reversible lithium storage was also observed in the LiF-Ti nanocomposite. Besides the conversion reaction, it is also noticed that extra lithium can be stored reversibly at the low voltage range after the formation of LiF-Ti nanocomposite. ${ }^{14}$ Jamnik and Maier explained such heterogeneous storage phenomenon as the interfacial charging. ${ }^{15,16}$

In previous reports on lithium storage through conversion reaciton, the nonaqueous electrolyte was used in the test cells. ${ }^{14,18}$ Consequently, the formation of the solid electrolyte interphase (SEI) is not avoidable. Therefore, the interfacial charging and the SEI evolve within the similar 
low voltage range, at least for the initial charge-discharge cycles. The SEI is covered on the formed LiX-M nanocompoosite. Experimentally, the transport properties of the lithium ions and electrons in the phase boundaries of the LiXM nanocomposite and the SEI film are difficult to be measured separately. One valuable in situ TEM investigations on the reaction of $\mathrm{Li}$ with $\mathrm{FeF}_{2}$ in a solid cell showed that $\mathrm{FeF}_{2}$ can be fully lithiated and converted into the LiF-Fe nanocomposite. ${ }^{17}$ Accordingly, Wang et al suggested that the massive interface formed between nanoscaled solid phases provides pathways for ionic transport during the conversion process. Since either $\mathrm{LiF}$ or $\mathrm{Li}_{2} \mathrm{O}$ or $\mathrm{M}$ is not lithium ion conductors, it is quite reasonable that lithium should diffuse through the phase boundaries of the LiX-M nanocomposites, although direct evidences are absent.

In addition, one thing is still unclear: for a given LiX-M nanocomposite, whether are the lithium at the lattice site in the LiX or the extra lithium inserted from the outside of the composite mobile in the nanocomposite? In order to clarify above issues, in this work, the LiF-Ti nanocomposite thin film electrodes are prepared and lithiated either by electrochemical or chemical method. Therefore, the ionic and electronic conductivity of the LiF-Ti nanocomposites with and without external lithium can be measured and compared.

\section{Experimental}

\section{1. Preparation of the Substrate Ti Electrodes for Measuring Conductivity}

The parallel electrodes were usually used in thin film conductivity measurement. ${ }^{11-12}$ A $100 \mu \mathrm{m}$ strip of photoresist was spin coated on the quartz substrate. The titanium electrodes were deposited by sputtering on the substrate. Then immersed the substrate into acetone solution for a while, the photoresist will be peeled off and the parallel Ti electrodes with a $100 \mu \mathrm{m}$ gap were prepared, as

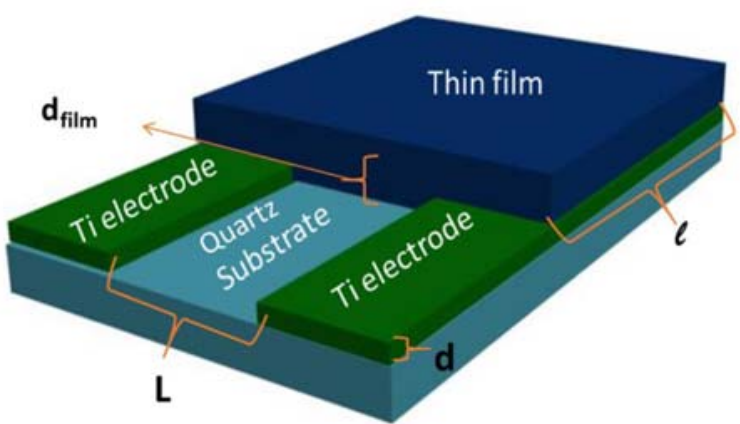

Figure 1. The scheme of the bottom parallel electrodes for transportation measurement

Table 1. Dimensions of the parallel electrode device for transportation measurement

\begin{tabular}{lc}
\hline Dimension & Value \\
\hline Thickness of thin film: $\boldsymbol{d}_{\text {film }}$ & $2.5 \mu \mathrm{m}$ or appr.300 nm \\
Length of thin film: $\boldsymbol{l}$ & $4 \sim 7 \mathrm{~mm}$ \\
Thickness of Ti electrode: $\boldsymbol{d}$ & $500 \mathrm{~nm}$ \\
Gap of two Ti electrodes: $\boldsymbol{L}$ & $100 \mu \mathrm{m}$ \\
\hline
\end{tabular}

shown in Figure 1. Table 1 shows the dimensions of the parallel electrode device for transportation measurement

The conductivity is obtained by formula: $\sigma=\frac{\mathrm{L}}{l \cdot d} \cdot \frac{1}{R}=\mathrm{k} \cdot \frac{1}{R}$, in which $\sigma$ has unit $\mathrm{S} / \mathrm{cm}, \mathrm{R}$ has unit $\Omega$, $\mathrm{k}$ is a constant value depends on the device dimension, here we take it as $520 \mathrm{~cm}^{-1}$.

\section{2. Preparation of the $\mathrm{LiF}-\mathrm{Ti}$ Nanocomposite Thin Film}

Yu et al. reported the LiF-Ti nanocomposite thin film prepared by PLD (pulse laser deposition). ${ }^{18}$ In this study,
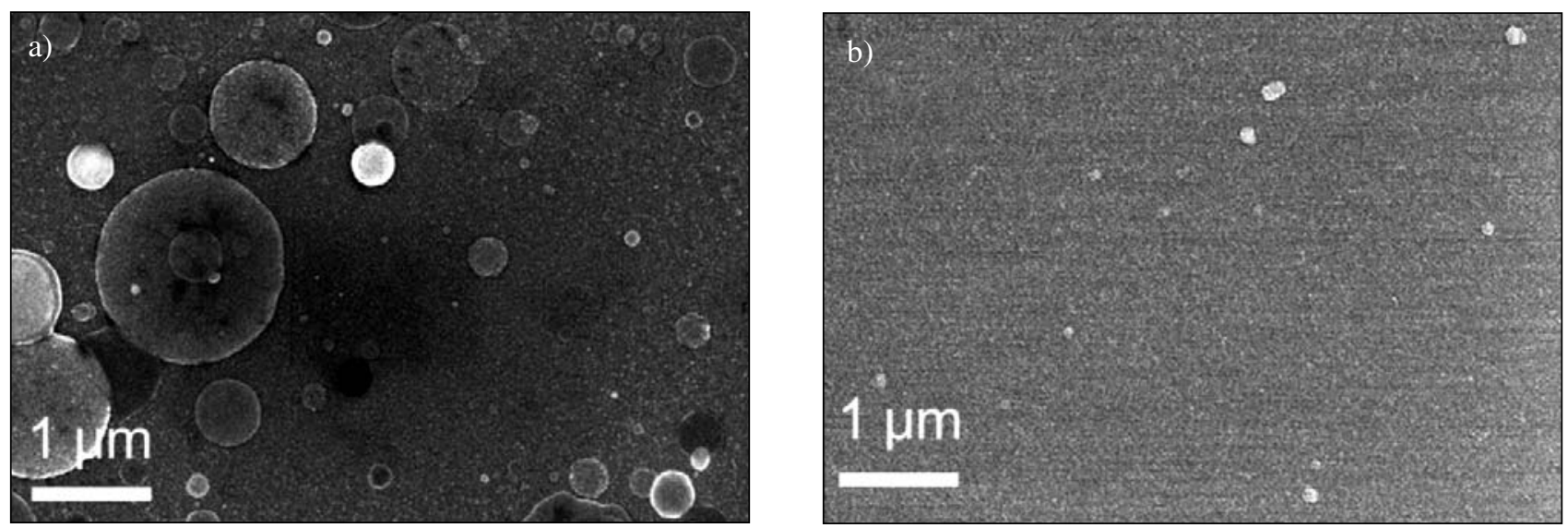

Figure 2. the surface morphology (by FE-SEM) of LiF-Ti nanocomposite thin films, prepared by (a) PLD and (b) co-sputtering 


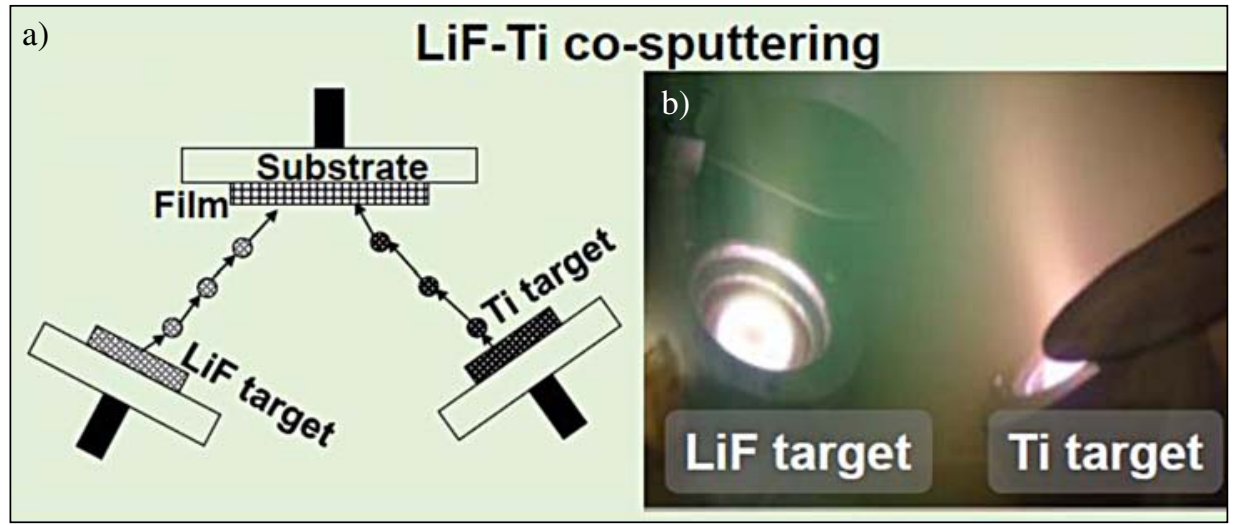

Figure 3. (a) the scheme and (b) photograph of the co-sputtering

we also repeated the PLD method to deposit the LiF-Ti thin film. As shown in Figure 2a, the particles of the thin film was not deposited homogeneously as reported previously, ${ }^{18}$ the size of some particles were as large as $1 \mu \mathrm{m}$. In order to improve the homogeneity of the thin film, the LiF and $\mathrm{Ti}$ components in the thin film were deposited by the RF-sputtering (Radio Frequency sputtering) and DC-sputtering (Direct Current Sputtering) respectively. As shown in Figu- re $2 \mathrm{~b}$, the LiF-Ti nanocomposite thin film prepared by the sputtering is much flatter and more homogeneous than the one prepared by PLD. In this work, the samples tested were all prepared by the co-sputtering method, Figure 3 shows the scheme and photograph of co-sputtering method.

Figures $4(\mathrm{a}-\mathrm{c})$ show the cross-section images and element analysis of the co-sputtered thin film by FE-SEM and Energy-dispersive elemental analysis (EDX). It can

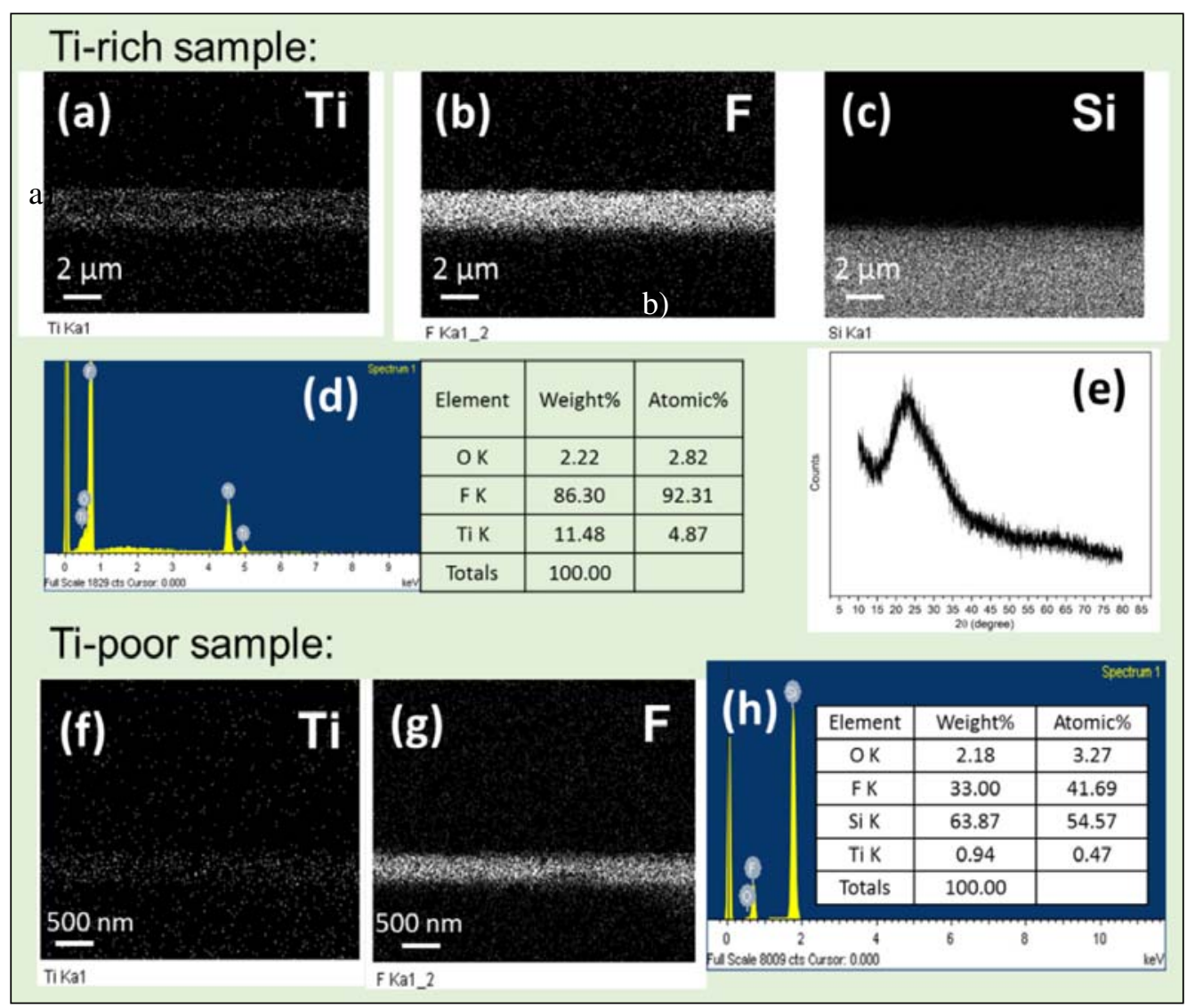

Figure 4. Element mapping (a, b, c: Ti-rich sample, f, g: Ti-poor sample), EDX (d: Ti-rich sample, h: Ti-poor sample) and XRD pattern (e: Ti-rich sample) of the co-sputtered LiF-Ti nanocomposite thin film 
be seen that the film is flat and the distribution of Ti and $\mathrm{F}$ elements is quite homogeneously. Atomic ratio of $\mathrm{F}$ to $\mathrm{Ti}$ is 19:1 roughly. No XRD peaks from $\mathrm{LiF}$ and $\mathrm{Ti}$ is found in Figure 4e, indicating that the composite thin film is composed of the nano-sized particles and the grain sizes of which are much smaller than that in our previous report. ${ }^{18}$ This sample is Ti-rich LiF-Ti composite. As the comparison, another sample of Ti-poor LiF-Ti nanocomposite is also prepared, and the atomic ratio of $\mathrm{F}$ to $\mathrm{Ti}$ is about 88:1 as shown in Figure $4 \mathrm{~h}$. Figures $4 \mathrm{f}$ and $4 \mathrm{~g}$ show the cross-section element analysis of the Ti-poor sample.

\subsection{Electrochemical Test and Electrochemical Lithiation}

The as prepared LiF-Ti nanocomposite thin film was immersed into a small electrochemical cell filled with organic electrolyte $\left(1 \mathrm{M} \mathrm{LiPF}_{6}\right.$ dissolved in ethylene carbo-

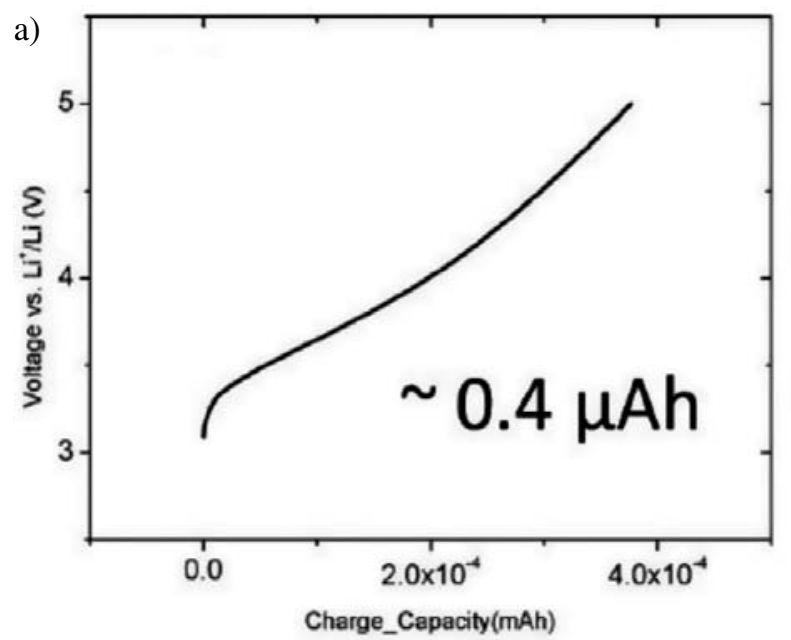

nate (EC) and dimethyl carbonate (DMC), 1:1 in volume). The lithium foil was also immersed into the electrolyte as the counter electrode of the cell. When the cell is charged firstly, the charging capacity is less than $0.4 \mu \mathrm{Ah}$, as shown in Figure 5a. While the cell is discharged firstly, then the capacity is above $40 \mu \mathrm{Ah}$ and the charging capacity is about $20 \mu \mathrm{Ah}$. As seen in Figure $5 \mathrm{~b}$, there is a significant irreversible capacity. It could be related to the formation of the SEI since the voltage range of the cell is already lower than $1.0 \mathrm{~V}$. Since the existence of the SEI cannot be excluded, the electrode prepared by electrochemical lithiation in nonaqueous electrolyte is not very reliable for investigating the conductivity.

\section{4. Chemical Lithiation}

In order to eliminate the possible influence from the SEI, the prepared nanocomposite thin film was chemi-

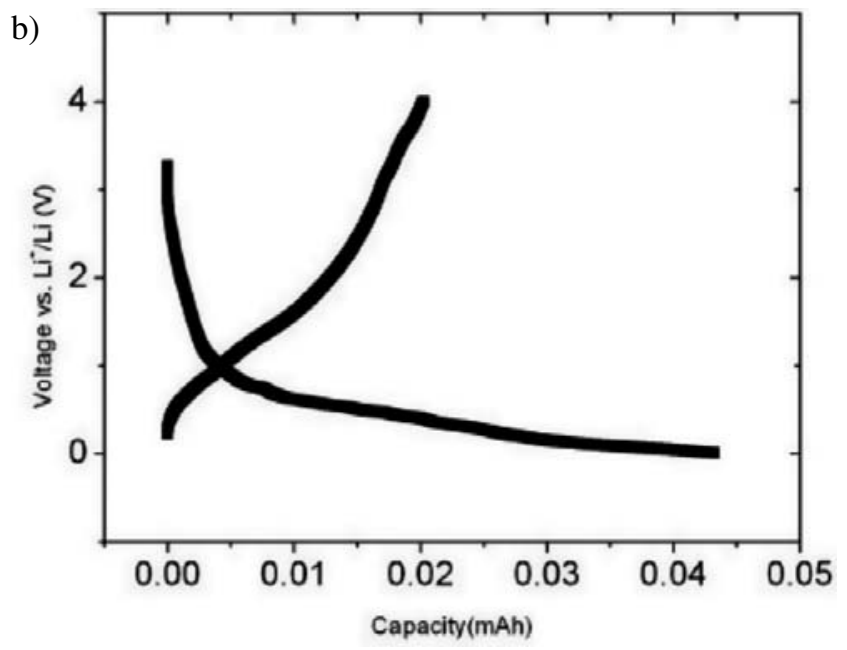

Figure 5. The first charge curve of the Li/LiF-Ti cell and the first discharge-charge curves of the $\mathrm{Li} / \mathrm{LiF}-\mathrm{Ti}$ nanocomposite cell at room temperature in $1 \mathrm{M} \mathrm{LiPF}_{6}$ dissolved in $\mathrm{EC}: \mathrm{DMC}, 1: 1$ in volume). $\mathrm{LiF}: \mathrm{Ti}=19: 1$ for atomic ratio.

a)

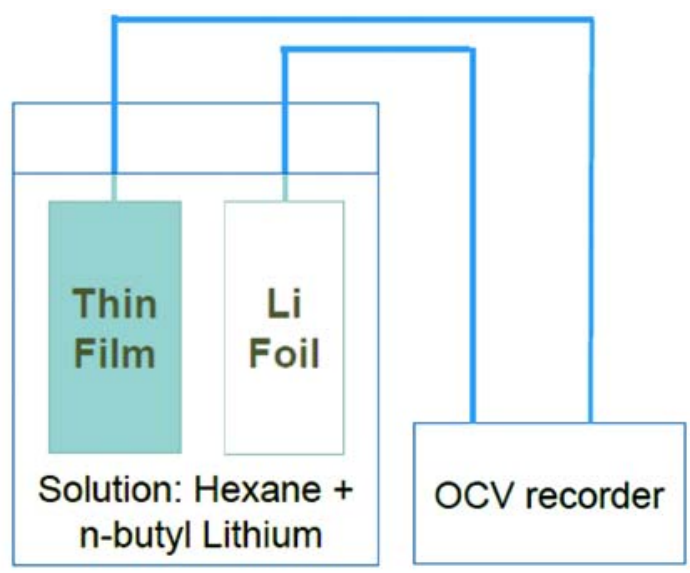

b)

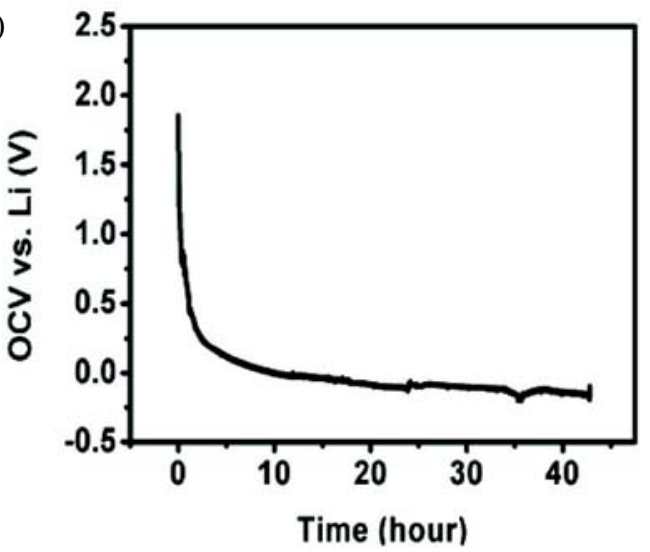

Figure 6. (a) The scheme of the chemical lithiation process and the tracking method for monitoring the lithiation level. (b) The recorded voltage of the cell during chemical lithiation. 
cally lithiated by immersing the thin film into the $20 \mathrm{~mL}$ hexane solution with $20 \mu \mathrm{L}$ n-butyl lithium (i.e. $1 \%$ o V/V). This chemical lithiation method has been known for long time. ${ }^{19}$ In order to track chemical lithiation level, a new cell was designed as shown in Figure 6a. The LiF-Ti thin film electrode was put into a cell with metal lithium electrode. Once the n-butyl lithium solution was dropped into the cell, the open circuit voltage (OCV) between the LiFTi electrode and $\mathrm{Li}$ was recorded. Since the OCV of the LiF-Ti electrode is only related to the content of inserted lithium, the record of the OCV can be used to track the chemical lithiation level, as shown in Figure 6b. After about 40 hours, the voltage deviation between lithium metal electrode and the LiF-Ti electrode remains constant, which means that the thin film electrode is fully lithiated.

\section{5. IV, IS, ITIC Measurement}

The electronic and ionic transport properties in the as prepared thin film and the electrochemically or chemically lithiated thin films were measured by the method of I-V curve (current-voltage curve), IS (impedance spectrum) and ITIC (isothermal transient ionic current). When the LiF-Ti thin film was lithiated electrochemically or chemically, it was taken out from the organic liquid electrolyte (1M LiPF 6 dissolved in EC: DMC, 1:1 in volume) or hexane solution with n-butyl lithium respectively. Then the sample was dried at RT under vacuum overnight. The dried and lithiated sample was sealed into a glass container and taken out from the glovebox for the following analysis. IV test was conducted by Agilent $4156 \mathrm{c}$ precision semiconductor parameter analyzer, with the scanning voltage ranging from $-1 \mathrm{~V}$ to $1 \mathrm{~V}$, and the scanning step set to $0.01 \mathrm{~V}$. IS test was conducted by IM6ex (Zahner, Germany), frequency range for test was between $1 \mathrm{MHz}$ and $0.1 \mathrm{~Hz}$, the amplitude of voltage was $10 \mathrm{mV}$, and the IS result was fitted by Zview. ITIC test was conducted by Agilent 4156c, the applied voltage bias between the two electrodes was $100 \mathrm{mV}$. The parallel electrodes device as described in Figure 1 was used for all of these tests, and the tests were conducted at room temperature.

The electronic conductivity of the thin film at room temperature (RT) can be obtained from the I-V curve. The total conductivity (including electronic conductivity and ionic conductivity) at RT can be obtained from IS measurement. As for the ITIC measurement, ${ }^{20-23}$ a constant voltage is applied across the thin film and the current response was measured using the Agilent 4156C. Since the electrode in this work was the deposited Ti thin film, it blocks the transport of the lithium ions. If the applied voltage is $U$ and the distance between the two Ti electrodes is $L$, the relationship between the current response and the time could be described as follows:

$$
J(t)=\frac{\sigma_{d c, e^{-}-U}}{L}+\frac{\sigma_{d c, L i}+U}{L} \exp \left(-\frac{\mu_{L i^{+}} U}{L^{2}} t\right)
$$

Where $J(t)$ is the current density, $t$ is the time that voltage applies on the sample, $\sigma_{d c, e^{-}}$is the electronic conductivity, $\sigma_{d c, L i, e^{-}}$is the ionic conductivity, $\mu_{L i^{+}}$is the mobility of the lithium ion. There are two items in the right side of the equation. The first item is related to the current density of electronic current. This item could be obtain by the classical ohm's law. The second item is related to the current density of ionic current. In our case of $\mathrm{LiF} / \mathrm{Ti}$, the lithium ion transportation will contribute to this item. Since the ion blocking electrode (i.e. Ti film electrode) was used during measurement, the lithium ion transportation will not remain as a constant. As the lithium ions move from one electrode to the other electrode and aggregated on the electrode. The ionic current density will obey the ohm's law at the beginning, but then decrease and at last disappear. The rate of ionic current decrease is related to the mobility of lithium ion $\mu_{L i+}$, the factor of describing

ionic current decreasing could be written as $\exp \left(-\frac{\mu_{L i^{+}}}{L^{2}} t\right)$.

The detailed derivation of this formula could be found in literatures. ${ }^{20-23}$ The electronic conductivity, ionic conductivity and mobility of lithium ion could be calculated by fitting the current response with the formula.

\section{Results and Discussion}

The co-sputtered LiF-Ti nanocomposite thin film before and after electrochemical lithiation show different current-voltage feature in Figure 7a. The IV curve of the pristine LiF-Ti thin film shows a linear IV curve within $\pm 1 \mathrm{~V}$ range, a typical ohmic behaviour. The conductivity is calculated from IV curves and increases from $3.6 \times 10^{-3} \mathrm{~S} / \mathrm{cm}$ to $7.3 \times 10^{-3} \mathrm{~S} / \mathrm{cm}$ after electrochemical lithiation. As mentioned above, the electrochemical lithiation may lead to the coverage of the insulating SEI film. Our conductivity measurement is performed based on the configuration in Figure 1. The SEI film layer, which is an electronic insulating and ionic conductor in many cases,${ }^{24}$ may cover the top of the LiF-Ti film. The SEI film can be regarded as in parallel with the deposited LiF-Ti film in view of electrode configuration and equivalent circuit. Therefore, the insulating SEI may have negligible effect on the measuring of the electronic conductivity.

Since LiF and Ti cannot accommodate extra inserted lithium within the lattice, the inserted lithium should stay at the phase boundaries between $\mathrm{LiF}$ and $\mathrm{Ti}$ in a charge separation way with the positive and negative charged carriers separated into countered sides of interfaces. Only when enough amount lithium is accumulated in the LiF-Ti composite, the state of lithium is approaching neutral state of lithium atom and the voltage of the Li/LiF-Ti cell is closed to $0 \mathrm{mV}$. Above this voltage, lithium should stay in a charge separation way. Both electrons and ions could be 

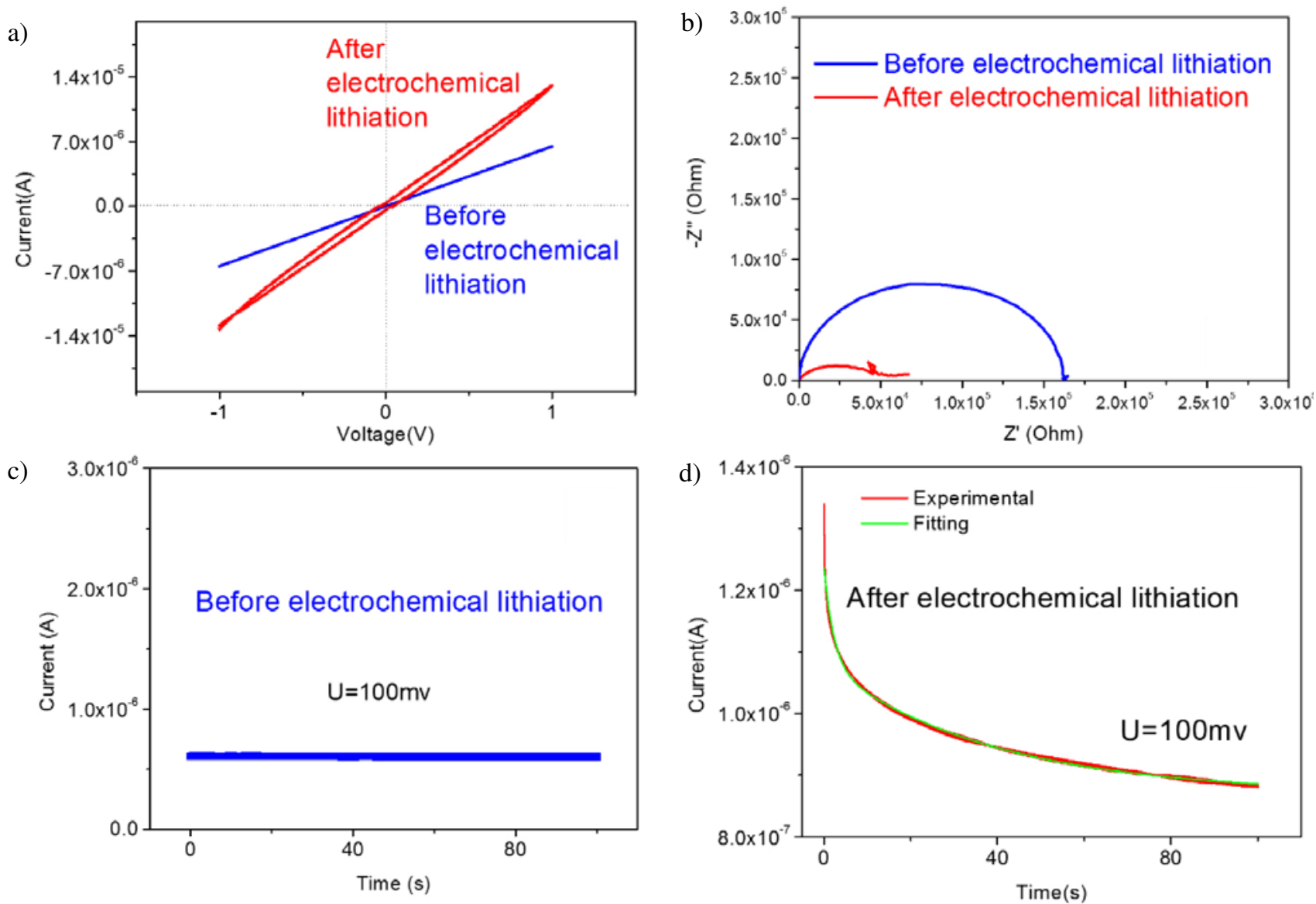

Figure 7. (a) IV curves, (b) IS curves, (c, d) ITIC curves of the pristine LiF-Ti ( $\mathrm{LiF}: \mathrm{Ti}=19: 1)$ electrode and the Ti-rich LiF-Ti electrode after electrochemical lithiation (i.e. $\mathrm{Li} / \mathrm{LiF}-\mathrm{Ti}$ cell is discharged to $5 \mathrm{mV}$ ).

mobile. IV measuring cannot distinguish the contribution from electronic conductivity and ionic conductivity. One fact should be noted. After the electrochemical lithiation, IV curves show a symmetrical hysteresis loop, implying a kind of reversible polarization behaviour. The appearance of the loop is quite reasonably caused by ionic transport behaviour in the electrochemically lithiated LiF-Ti nanocomposite in an ion block system. Since the deviation of the loop is not significant, the ionic conductivity should be lower compared to electronic conductivity. In addition, the absence of the loop in the pristine LiF-Ti nanocomposite thin film means that its ionic conductivity could be negligible.

Impedance spectrum of the pristine LiF-Ti composite thin film shows a feature of a semi-circle. This indicates that the LiF-Ti composite does not act as a metal. Ti should exist in the composite as isolated domains, as supported by element mapping in Figure 4. The electrical behaviour of this composite likes a typical composite capacitor. After electrochemical lithiation, the semicircle is compressed and the diameter decreases significantly. The measured total conductivity increases from $3.2 \times 10^{-3}$ $\mathrm{S} / \mathrm{cm}$ to $1 \times 10^{-2} \mathrm{~S} / \mathrm{cm}$ as shown in Table 2 . The tendency consists with IV measurement.
ITIC analysis can provide information of the electronic and ionic conductivity. As shown in Figure 7c and $7 \mathrm{~d}$, ITIC curves are quite different before and after electrochemical lithiation. Figure $7 \mathrm{~d}$ shows typical ionic transport behaviour. Electronic conductivity of the pristine LiF-Ti thin film is $3.12 \times 10^{-3} \mathrm{~S} / \mathrm{cm}$ and the ionic conductivity is negligible. Total conductivity is determined by the electronic conductivity. After electrochemical lithiation, electronic conductivity is increased to $4.5 \times$ $10^{-3} \mathrm{~S} / \mathrm{cm}$ and ionic conductivity is as high as $3.3 \times$ $10^{-3} \mathrm{~S} / \mathrm{cm}$. Total conductivity is $7.8 \times 10^{-3} \mathrm{~S} / \mathrm{cm}$. The transference number of $\mathrm{t}_{\mathrm{e}-}$ and $\mathrm{t}_{\mathrm{Li}+}$ is 0.58 and 0.42 .

All results from IV, IS and ITIC confirms that electrochemically lithiated LiF-Ti nanocomposite thin film shows higher electronic and ionic conductivity compared than pristine LiF-Ti thin film. As mentioned above, the influence of the SEI could be negligible but not very clear in above measurements. Therefore, chemically lithiated samples are also measured.

In order to emphasize the effect of the lithiation, the ratio of $\mathrm{LiF}$ to Ti increase further to form a Ti-poor nanocomposite. This time, the sample composition changes from original 19:1 form LiF: Ti to a Ti-poor composite $(\mathrm{LiF}: \mathrm{Ti}=88: 1)$. 
The transport behaviours of chemically lithiated LiF-Ti nanocomposite are similar as Figure 7. Pristine LiF-Ti $(88: 1)$ composite thin film show a very high resistance in Figure 8a, 8c and 8e. This is reasonable since the ratio of $\mathrm{Ti}$ is decreased significantly.

After chemical lithiation, the IV curve shows a very significant loop. The impedance spectrum shows a linear slope and the ITIC curve shows an exponential decay as Figure 8(f). All features indicate that both electronic and ionic conductivity are improved significantly. The related data are listed in Table 2.

It can be seen from Table 2 that the electronic conductivity is determined to the ratio of Ti in the composite.

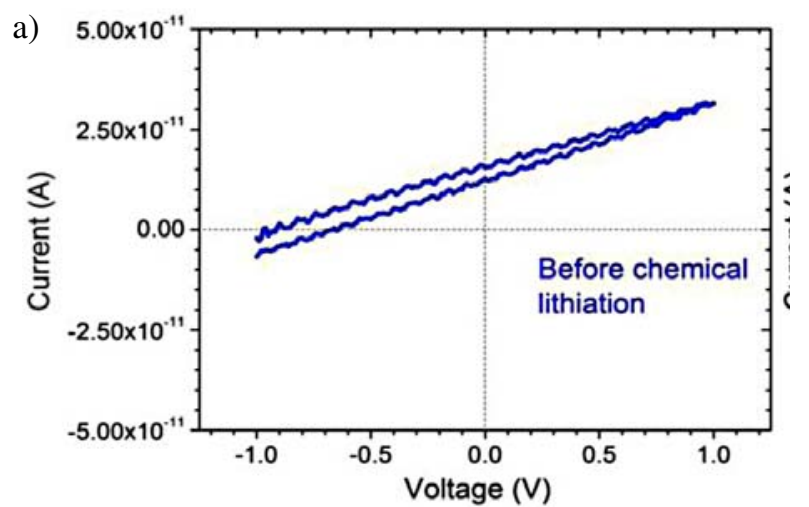

c)

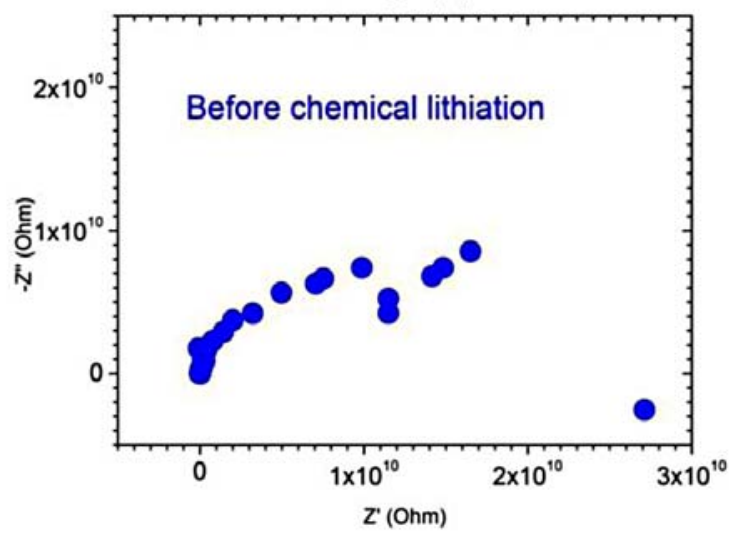

e)

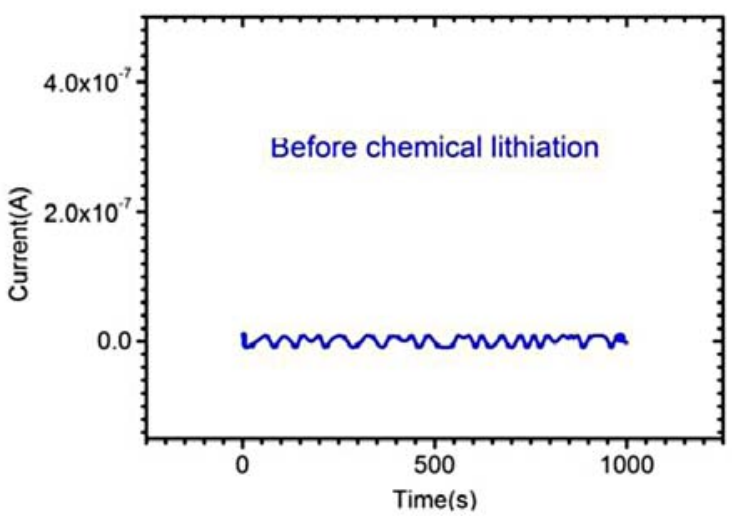

This is reasonable in view of percolation and tunneling effect of Ti grains. It is quite clear that pristine LiF-Ti thin films have poor ionic conductivity. The ionic conductivity of $\mathrm{LiF}$ single crystal at room temperature is $1 \times 10^{-19}$ $\mathrm{S} / \mathrm{cm}^{25}$. The amorphous thin film of $\mathrm{LiF}$ shows an ionic conductivity of $1 \times 10^{-10} \mathrm{~S} / \mathrm{cm}^{26}$. Recently, Li et al reported that the $\mathrm{LiF} / \mathrm{MO}\left(\mathrm{Al}_{2} \mathrm{O}_{3}, \mathrm{SiO}_{2}, \mathrm{TiO}_{2}\right)$ heterogeneous bilayer thin film shows enhanced ionic conductivity due to the space charge effect and interfacial disorder. ${ }^{27,}{ }^{28} \mathrm{In}$ our case of $\mathrm{LiF}-\mathrm{Ti}$, the existence of the second phase $\mathrm{Ti}$ did not show a measurable enhancement on the ionic conductivity of LiF. In the view of the second phase, Ti was the metal in nano size, it provides no lattice site or lattice

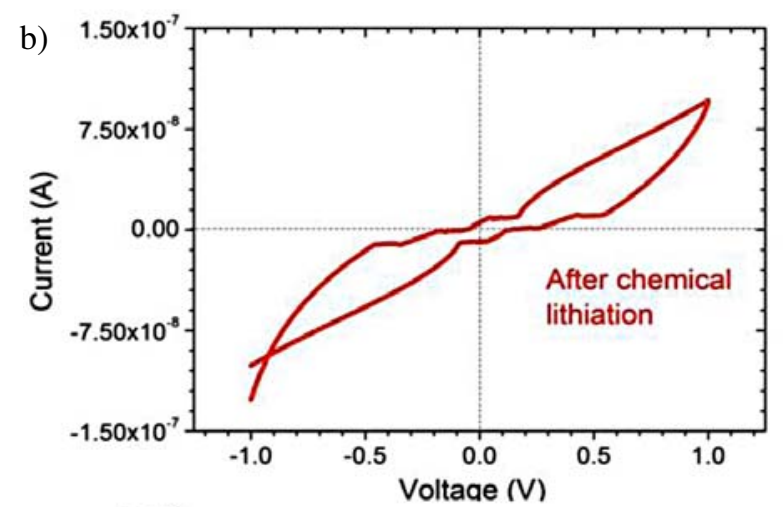

d)
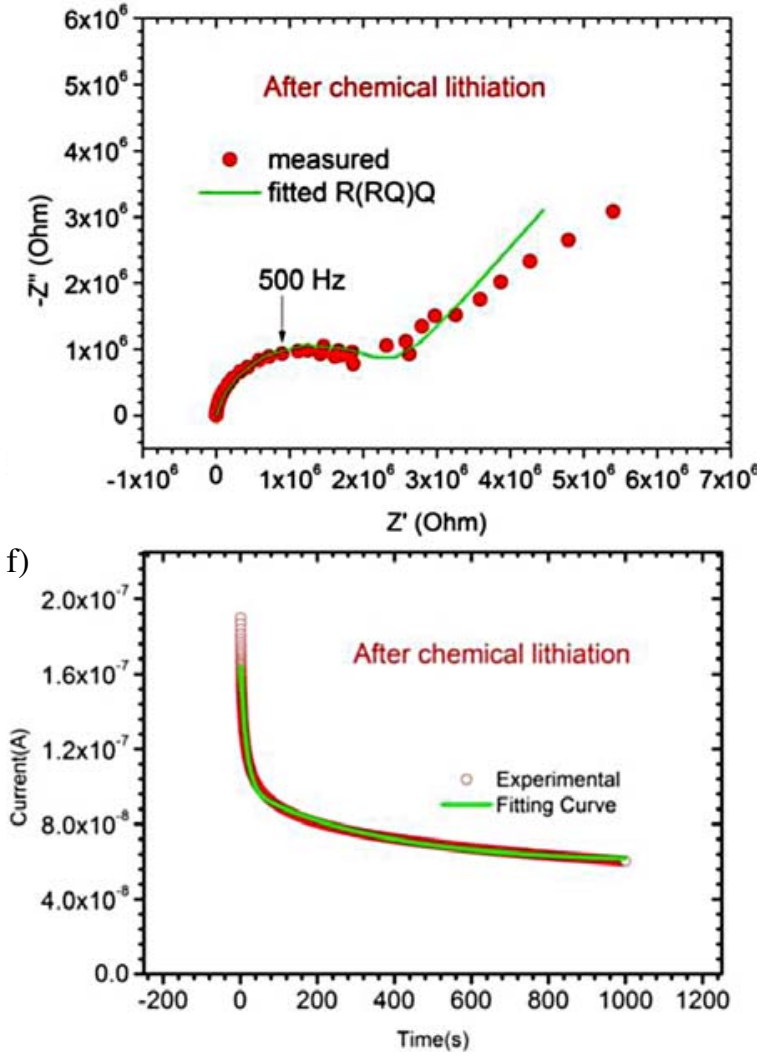

Figure 8. The IV (a, b), IS (c, d) and ITIC (e, f) measurement results of the LiF-Ti ( $\mathrm{LiF}: \mathrm{Ti}=88: 1)$ nanocomposite thin film at room temperature before and after chemical lithiation. The pristine Ti-poor LiF-Ti sample shows a relative low electric conductivity due to the Ti deficiency. Thus the signal of IV curve was affected by noises. 
Table 2. RT conductivity of the LiF-Ti nanocomposite before and after electrochemical and chemical lithiation (measured by IV, IS and ITIC).

\begin{tabular}{|c|c|c|c|c|c|c|}
\hline Measuring method & IV & IS & & & & \\
\hline $\begin{array}{l}\text { Conductivity } \\
\text { Unit }\end{array}$ & $\begin{array}{c}\sigma_{\mathrm{e}-} \\
\mathrm{S} / \mathrm{cm}\end{array}$ & $\begin{array}{c}\sigma_{\text {total_IS }} \\
\mathrm{S} / \mathrm{cm}\end{array}$ & $\begin{array}{c}\sigma_{\mathrm{e}-} \\
\mathrm{S} / \mathrm{cm}\end{array}$ & $\begin{array}{c}\sigma_{\mathrm{Li+}} \\
\mathrm{S} / \mathrm{cm}\end{array}$ & $\stackrel{\mu_{\mathrm{Li+}}}{\mathrm{cm}^{2} / \mathrm{V} \mathrm{s}}$ & $\begin{array}{c}\sigma_{\text {total_TTIC }}=\sigma_{\mathrm{e}-}+\sigma_{\mathrm{Li}+} \\
\mathrm{S} / \mathrm{cm}\end{array}$ \\
\hline & & & ch LiF-Ti sa & ple (LiF:Ti & $9: 1)$ & \\
\hline Pristine LiF-Ti & $3.6 \times 10^{-3}$ & $3.2 \times 10^{-3}$ & $3.1 \times 10^{-3}$ & Very low & Very low & $3.1 \times 10^{-3}$ \\
\hline Electrochemically lithiated LiF-Ti & $7.3 \times 10^{-3}$ & $1 \times 10^{-2}$ & $4.5 \times 10^{-3}$ & $3.3 \times 10^{-3}$ & $2.4 \times 10^{-4}$ & $7.8 \times 10^{-3}$ \\
\hline & & & or LiF-Ti sa & ple(LiF:Ti= & & \\
\hline Pristine LiF-Ti & $5.0 \times 10^{-9}$ & $5.0 \times 10^{-8}$ & Very low & Very low & Very low & Very low \\
\hline Chemically lithiated LiF-Ti & $3.0 \times 10^{-5}$ & $2.6 \times 10^{-4}$ & $6.8 \times 10^{-5}$ & $1.3 \times 10^{-4}$ & $4.0 \times 10^{-5}$ & $2.0 \times 10^{-4}$ \\
\hline
\end{tabular}

vacancies for the storage and transportation of lithium. Moreover, the sputtered LiF was totally amorphous according to the $\mathrm{X}$-ray analysis. As mentioned above, LiF phase cannot provide lattice sites for the storage and interior channels for the transportation of lithium. Therefore, the only possible ionic transport channels are the phase boundary. In our case of LiF-Ti, the lithium from the external source may stay and migrate along the phase boundary between the $\mathrm{LiF}$ and $\mathrm{Ti}$.

Therefore, in spite of poor ionic conductivity of LiF-Ti nanocomposite thin film, it is no doubt that both electrochemically and chemically lithiated thin films show much enhanced ionic conductivity and electronic conductivity. The enhancement mechanism is related to the external lithium stayed at the phase boundaries in the LiF-Ti nanocomposite in a form of charge separation. Unfortunately, the local structure of the lithiated LiF-Ti nanocomposite is still not known due to the difficulty in characterization.

Currently, exploring superionic conductor as solid electrolyte and enhancing ionic transport property of the electrode and the interface are two very important targets for developing advanced lithium batteries. Most of efforts are focused on tuning the intrinsic ionic transport properties of the host lattice. Not the first time but from a new viewpoint, our finding emphasizes that tuning phase boundary by introducing the second phase and considering the transport of external ions could be important and new strategies, needing comprehensive investigations.

\section{Summary}

The electronic conductivity and ionic conductivity of the LiF-Ti nanocomposite thin film before and after electrochemical and chemical lithiation are measured using IV, IS and ITIC methods. It is found that the electronic conductivity of the LiF-Ti film is determined by the ratio of Ti and can be enhanced after the insertion of lithium. The ionic conductivity of pristine LiF-Ti nanocomposite is poor and no significant space charge enhancement effect is observed. Electrochemical and chemical lithiation can improve the ionic conductivity of the LiF-Ti nanocomposite thin films to a level of $1 \times 10^{-3} \mathrm{~S} / \mathrm{cm}$ at room temperature. This finding indicates that even when both phases of $\mathrm{LiF}$ and $\mathrm{Ti}$ are not ionic conductor and cannot accommodate extra lithium, external lithium at phase boundaries can lead to the high ionic and electronic conductivity. It means that phase boundary composed of ionic insulating phases can be also utilized as fast ionic channels.

\section{Acknowledgement}

Financial supports from NSFC project (51325206), Beijing S\&T Project (Z13111000340000), 973 project (2012CB932900) and »Strategic Priority Research Program « of the Chinese Academy of Sciences, Grant No. XDA0901010000) are appreciated.

\section{Reference}

1. Carl Wagner, Prog. Solid State Chem., 1975, 10, 3-16. http://dx.doi.org/10.1016/0079-6786(75)90002-3

2. J. Jamnik, S. Pejovnik, J. Maier, Electrochim. Acta, 1993, 38, 1975-1978.

http://dx.doi.org/10.1016/0013-4686(93)80326-U

3. Joachim Maier, Prog. Solid State Chem., 1995, 23, 171-263. http://dx.doi.org/10.1016/0079-6786(95)00004-e

4. R. C. Agrawal, R. K. Gupta, J. Mater. Sci., 1999, 34, 1131-1162. http://dx.doi.org/10.1023/A:1004598902146

5. J. Jamnik, J. Fleig, M. Leonhardt, J. Maier, J. Electrochem. Soc., 2000, 147, 3029-3035.

http://dx.doi.org/10.1149/1.1393643

6. Philippe Knauth, Harry L. Tuller, J. Am. Ceram. Soc., 2002, $85,1654-1680$.

http://dx.doi.org/10.1111/j.1151-2916.2002.tb00334.x

7. Jian Gao, Yu-Sheng Zhao, Si-Qi Shi, Hong Li, Chin. Phys. $B$, 2016, 25, 018211 .

http://dx.doi.org/10.1088/1674-1056/25/1/018211

8. C. C. Liang, J. Electrochem. Soc., 1973, 120, 1289-1292. http://dx.doi.org/10.1149/1.2403248

9. J. Jamnik, J. Maier, Solid State Ionics, 1997, 94, 189-198. http://dx.doi.org/10.1016/S0167-2738(96)00600-5

10. J. Jamnik, J. Maier, Solid State Ionics, 1999, 119, 191-198. 
http://dx.doi.org/10.1016/S0167-2738(98)00502-5

11. N. Sata, K. Eberman, K. Eberl, J. Maier, Nature, 2000, 40, 946-949. http://dx.doi.org/10.1038/35050047

12. ; , Adv. Mater., 2009, 21, 2619-2631. http://dx.doi.org/10.1002/adma.200900412

13. P. Poizot, S. Laruelle, S. Grugeon, L. Dupont and J. M. Tarascon, Nature, 2000, 407, 496-499. http://dx.doi.org/10.1038/35035045

14. H. Li, G. Richter, J. Maier, Adv. Mater., 2003, 15, 736-739. http://dx.doi.org/10.1002/adma.200304574

15. J. Jamnik, J. Maier, Phys. Chem. Chem. Phys., 2003, 5, 5215. http://dx.doi.org/10.1039/B309130A

16. J. Maier, Nature Mater., 2005, 4, 805-815. http://dx.doi.org/10.1038/nmat1513

17. F. Wang, R. Robert, N. A. Chernova, N. Pereira, F. Omenya, F. Badway, X. Hua, M. Ruotolo, R. Zhang, L. Wu, V. Volkov, D. Su, B. Key, M. S. Whittingham, C. P. Grey, G. G. Amatucci, Y. Zhu and J. Graetz, J. Am. Chem. Soc., 2011, 133, 18828-18836. http://dx.doi.org/10.1021/ja206268a

18. X. Q. Yu, J. P. Sun, K. Tang, H. Li, X. J. Huang, L. Dupont and J. Maier, Phys. Chem. Chem. Phys., 2009, 11, 9497-503. http://dx.doi.org/10.1039/b908149f
19. M. S. Whittingham, J. Electrochem. Soc., 1977, 124, 1387. http://dx.doi.org/10.1149/1.2133659

20. G. Greeuw and B. J. Hoenders, J. Appl. Phys., 1984, 55, 3371. http://dx.doi.org/10.1063/1.333376

21. Greeuw, G. and Verwey, J. F. J. Appl. Phys., 1984, 56, 2218. http://dx.doi.org/ 10.1063/1.334256

22. Watanabe, M., Rikukawa, M., Sanui, K. and Ogata, N. J. Appl. Phys., 1985, 58, 736. http://dx.doi.org/ 10.1063/1.336191

23. G. Frenning, M. Strømme, J. Appl. Phys., 2001, 90, 5570. http://dx.doi.org/10.1063/1.1412585

24. F. Luo, G. Chu, X. Xia, B. Liu, J. Zheng, J. Li, H. Li, C. Gu, L. Chen, Nanoscale, 2015, 7, 7651-7658. http://dx.doi.org/10.1039/C5NR00045A

25. Gary Geschwind, J. Phys. Chem. Solids, 1968, 30, 16311635. http://dx.doi.org/10.1016/0022-3697(69)90225-X

26. Tetsui Oi, Mater. Res. Bull., 1984, 19, 451-457 http://dx.doi.org/10.1016/0025-5408(84)90105-3

27. Chilin Li, Joachim Maier, Solid State Ionics, 2012, 225, 408-411. http://dx.doi.org/10.1016/j.ssi.2012.02.036

28. Chilin Li, Lin Gu, Joachim Maier, Adv. Funct. Mater., 2012, 22, 1145-1149. http://dx.doi.org/10.1002/adfm.201101798

\section{Povzetek}

S pomočjo različnih metod, kot so: impedančna spektroskopija (IS), tokovno-napetostnih krivulj (IV) in izotermičnih prehodnih tokov (ITIC), smo merili elektronsko in ionsko prevodnost Li-F-Ti naokompozitnih filmov pripravljenih s ko-pršenjem. Ugotovili smo, da je ionska prevodnost Li-F-Ti naokompozitnih filmov zelo nizka. Po elektrokemijski in kemijski litiaciji so ionske prevonosti narasle na $10^{-3}$ in $10^{-4} \mathrm{~S} / \mathrm{cm}$. Omenjeni fenomen kaže na možnost tvorbe, za zunaji litij, ionsko prevodnih kanalov na faznih mejah med zrni LiF in Ti v nanokompozitu. S pomočjo naših rezultatov predlagmo novo strategijo, kako krojiti ionske in mešano-ionske prevodnike. 